NBER WORKING PAPER SERIES

\title{
THE EFFECT OF CONVENTIONAL AND UNCONVENTIONAL MONETARY POLICY RULES ON INFLATION EXPECTATIONS: THEORY AND EVIDENCE
}

\author{
Roger E.A. Farmer \\ Working Paper 18007 \\ http://www.nber.org/papers/w18007 \\ NATIONAL BUREAU OF ECONOMIC RESEARCH \\ 1050 Massachusetts Avenue \\ Cambridge, MA 02138 \\ April 2012
}

This paper was prepared for a special issue of the Oxford Review of Economic Policy on Unconventional Monetary Policy. I would like to thank Christopher Bowdler for inviting me to submit a paper to this issue and David Vines and an anonymous referee for their comments on an earlier version of this paper. I would also like to thank Hanno Lustig for providing me with data on inflation swaps that I use to illustrate the effects of quantitative easing on the financial markets and C. Roxanne Farmer for editorial assistance. The views expressed herein are those of the author and do not necessarily reflect the views of the National Bureau of Economic Research.

NBER working papers are circulated for discussion and comment purposes. They have not been peerreviewed or been subject to the review by the NBER Board of Directors that accompanies official NBER publications.

(C) 2012 by Roger E.A. Farmer. All rights reserved. Short sections of text, not to exceed two paragraphs, may be quoted without explicit permission provided that full credit, including $(\mathbb{C}$ notice, is given to the source. 
The Effect of Conventional and Unconventional Monetary Policy Rules on Inflation Expectations: Theory and Evidence

Roger E.A. Farmer

NBER Working Paper No. 18007

April 2012, Revised July 2012

JEL No. E31,E4

\begin{abstract}
This paper has three parts. Part 1 constructs a classical economic model of inflation, augmented by a complete set of financial markets; I call this the core monetary model. Part 2 develops a series of calibrated examples to illustrate how the core monetary model explains the history of inflation after WWII and Part 3 provides evidence to show that the unconventional monetary policy, followed in the wake of the 2008 financial crisis, was effective in stabilizing inflation expectations. The core monetary model provides a unified framework to explain how an interest rule can be used to control inflation in normal times, and to explain the purpose of unconventional monetary policy when policy attains the zero lower bound. I argue that management of the variation in the composition of the Fed's balance sheet, is an important tool in a central bank's arsenal that can be used to help prevent deflation in the wake of a financial crisis.
\end{abstract}

Roger E.A. Farmer

UCLA

Department of Economics

Box 951477

Los Angeles, CA 90095-1477

and NBER

rfarmer@econ.ucla.edu 


\section{(I) Introduction}

This paper has three parts. Part 1 constructs a classical economic model of inflation, augmented by a complete set of financial markets; I call this new variant, the core monetary model. Part 2 develops a series of calibrated examples to illustrate how this model explains the history of inflation after WWII and Part 3 provides evidence to show that the unconventional monetary policy, followed in the wake of the 2008 financial crisis, was effective in stabilizing inflation expectations. I argue that management of the variation in the composition of the Fed's balance sheet, is an important tool in a central bank's arsenal that can be used to help prevent deflation in the wake of a financial crisis.

Most macroeconomic models developed in the past forty years contain a single representative agent who makes rational decisions and forms rational expectations of future prices. These strong assumptions have been widely criticized in the wake of the 2008 crisis. While some criticisms of modern macroeconomic models are valid, I will argue here that it would be a mistake to abandon the rational agent framework entirely. Instead, we should keep those parts of the paradigm that have been successful and replace those parts that have not.

Classical economists developed the real business cycle model (RBC) to explain economic fluctuations as the optimal responses of a rational agent to productivity shocks. When augmented by a monetary sector, the classical RBC model also provides a theory of the connection between money, interest rates and prices. ${ }^{2}$

In Part 1 of this paper, I develop the classical model further by adding complete markets for financial assets. This development is important because it allows me to describe the channel through which monetary policy influences inflation when the interest rate is at the zero lower bound. I refer to the RBC model, augmented with a monetary and a financial sector, as the core monetary model.

In Part 2 of the paper, I use this core monetary model to explain the theory of inflation developed by monetary economists in the past two decades. This theory has two key ingredients. The first is that agents have rational expectations. The second is that the central bank follows a rule. I demonstrate, with a series of calibrated examples, that the combination of these two ingredients provides a successful explanation of the history of post-war inflation. Because the core monetary model contains a complete set of financial assets, I am also able to use it to demonstrate how monetary policy was used successfully to manage inflationary expectations when the interest rate approached zero, following the collapse of Lehman Brothers in September of 2008.

During most of the post-war period, monetary policy in the US was conducted through the purchase and sale of three-month treasury bills on the open market. I refer to this as conventional

\footnotetext{
${ }^{2}$ See, for example, Cooley and Hansen (1989).
} 
monetary policy. In the wake of the 2008 financial crisis, the Fed lowered the interest rate close to zero and conventional monetary policy became ineffective; the interest rate could not be lowered further. At this point, the Fed began to engage in unconventional monetary policy in which it extended credit to the private economy through the purchase of a variety of assets including mortgage-backed securities and long-maturity government bonds.

The current debate about the role of monetary policy is not just about the effects of policy on inflation. It is also about the effectiveness of monetary policy in helping the economy to recover from a recession. Because the core monetary model assumes that output is determined by preferences, endowments and technology, it does not explain the effect of monetary policy on real economic activity. However, the model can be easily adapted to study that issue. For example, one could replace the assumption that output is determined by technology shocks with a theory of incomplete factor markets as in Farmer (2006, 2008, 2010, 2013). When expectations are driven by a belief function, as in Farmer (1991, 2002), the incomplete factor market model provides a channel through which monetary policy may have permanent effects on unemployment. $^{3}$

It is one thing to show that unconventional monetary policy could influence inflation in theory. But does it work that way in practice? In Part 3 of the paper I show that a big increase in the Fed's balance sheet in the autumn of 2008 coincided closely with a big increase in inflation expectations. Further, turning points in the stock market in March of 2009 and April of 2010 coincided closely with the beginning and end of Fed purchases of mortgage-backed-securities. It is unlikely that the simultaneous occurrence of large changes in the Fed's balance sheet with large changes in asset price movements was coincidental. I conclude that the core monetary model developed in this paper can explain both conventional and unconventional roles of monetary policy and is consistent with the asset price movements observed in practice.

\section{(II) Part 1: The core monetary model}

During World War II, the Federal Reserve in the United States was committed to keep interest rates low to help the Treasury pay for the war. ${ }^{4}$ This commitment ended in 1951, and starting in

${ }^{3}$ Kocherlakota (2012) uses the term, incomplete labor markets, to refer to models where there is a missing labor supply curve. Kocherlakota's usage mirrors the concept of incomplete factor markets originating in Farmer (2006, page12) without providing a specific microfoundation for the absence of a labor supply equation. The assumption of incomplete factor markets (Farmer, 2006, 2008, 2010, 2013) is distinct from both classical (Chari et. al. 2009) and New-Keynesian (NK) models (Clarida et. al. 1999, Cúrdia and Woodford 2010) which assume that prices are sticky. The NK model preserves the natural rate hypothesis, a property that is not a good characterization of the data (Beyer and Farmer 2007) and is particularly hard to defend in the wake of the 2008 financial crisis where unemployment rates in most western nations have remained persistently high for more than three years.

${ }^{4}$ The commitment ended when the Fed and the Treasury signed an agreement, the Accord. For an account of this period see the Federal Reserve Bank of Richmond Economic Quarterly, Special Issue, winter (2001). 
the early 1960s, the Fed followed a policy of raising the interest rate in response to increases in inflation or increases in growth, and lowering it as inflation subsided or as the economy fell into recession.

The period from 1960 through 1979 was characterized by a slow buildup of inflation and unemployment, accompanied by volatile and high inflation and volatile growth (Clarida et. al. 2000). The combination of high inflation and high unemployment was unprecedented in the U.S. and in November of 1979, Paul Volcker was brought in as Chairman of the Federal Reserve Board, tasked with bringing inflation under control.

Beginning in 1983, the Fed commenced a policy of responding to inflation by aggressively raising the short-term interest rate. The result was a period of remarkable stability in which inflation and unemployment fell, and inflation, growth and unemployment all became less volatile. Because of increased stability in inflation, unemployment and GDP growth, the period from 1983 to 2006 is referred to as the Great Moderation (Stock and Watson, 2002). ${ }^{5}$

The core monetary model explains the Great Moderation as the response of a rational agent to a change in the Fed's monetary policy. This explanation has two main features; (1) agents form expectations rationally and (2) the behavior of the Federal Reserve is predictable and described by a policy rule.

\section{(i) Rational expectations and stationarity}

Rational expectations macroeconomic models are represented by stationary solutions to stochastic difference equations of the kind described in equations (1) and (2).

$$
\begin{gathered}
\mathrm{s}^{\prime}=g\left(\mathrm{~s}, \varepsilon^{\prime}\right), \\
X=\phi(\mathrm{s}) .
\end{gathered}
$$

$S$ is a vector of state variables in the current period, $X$ is a set of variables of interest and a prime on a variable indicates that it occurs in the subsequent period. $\varepsilon^{\prime}$ is a random event that causes the state to change from $s$ to $s^{\prime} .6$

\footnotetext{
${ }^{5}$ Bernanke and Mishkin (1992) and Clarida et. al. (2000), attribute the Great Moderation to improved monetary policy. Competing explanations include: good luck (Sims and Zha 2006) and changes in technology (McConnellPerez-Quiros 2000).

${ }^{6}$ More generally, the state may include economic variables such as the capital stock or the distribution of wealth across households. This makes the equations more complicated but it does not alter the principle that economic systems are modeled with stationary stochastic equations like those described in equations (1) and (2).
} 
Equation (1) tells us that the state evolves according to a rule, captured by the function $g\left({ }^{\cdot}\right)$. Equation (2) tells us that the economic variables, $X$, depend on the state, captured by the function $\phi(s)$.

In principle, the variables, $X$, might be changing over time even if the state remains constant. By studying stationary solutions to stochastic difference equations, we are assuming this does not happen. Every time the economy enters state, $s$, we would expect to see the same values of all of the observable variables.

Stationarity and rational expectations go hand in hand. The theory of rational expectations tells us that the agents who populate our models should use correct, model consistent, probability densities to predict future inflation rates. Stationarity is an important component of the theory because it implies that agents have a reasonable chance, through observation, to learn what these probability densities are in practice. Expectations are built into the function $\phi(\mathrm{s})$, which represents the solution to a complete macroeconomic model.

\section{(ii) Asset pricing and financial markets}

Modern financial markets display a staggering degree of complexity and it is possible to make contingent trades on almost any conceivable set of future events. To make computations easier, theorists break the vast array of financial assets down into simpler units called Arrow securities, named after the economist Kenneth Arrow (Arrow 1964). An Arrow security is a promise to deliver one dollar in state, $s^{\prime}$, if and only if state, $s^{\prime}$, occurs. Financial economists have shown that every financial asset can be represented as a collection of Arrow securities.

The price of an Arrow security is described by a function, $Q\left(s, s^{\prime}\right)$, called the pricing kernel. ${ }^{7}$ Financial economists, employed by investment banks and hedge funds, use this concept on a daily basis to decide how much an asset is worth.

For example, consider an asset that costs $q(s)$ today and pays a stream of dividends $\left\{d\left(s^{\prime}\right), d\left(s^{\prime \prime}\right)\right.$, $\ldots\}$ in a sequence of future states $\left\{s^{\prime}, s^{\prime \prime}, \ldots\right\}$. It might be a share in a company that pays a dividend $d\left(\mathrm{~s}^{\prime}\right)$ or it might be a bond that pays a coupon, $d\left(\mathrm{~s}^{\prime}\right)=d$, in every state. The asset pricing equation, gives us a way of pricing this security,

$$
q(s)=\sum_{s^{\prime}}\left\{Q\left(s, s^{\prime}\right)\left[q\left(s^{\prime}\right)+d\left(s^{\prime}\right)\right]\right\} .
$$

The left side of this expression is the price of the security today. The right side sums the payoffs of the security tomorrow over all possible subsequent states weighted by the pricing kernel.

\footnotetext{
${ }^{7}$ In richer models, the state next period may be represented by an interval $[\mathrm{a}, \mathrm{b}]$ rather than by a single value. In that more general environment the first argument of the function $Q(\because$,$) is the current value of the state and the second$ argument is a set of values. A function like this, where the second argument is a set, is called a kernel.
} 
Notice that the payoffs in each future state include any dividend that the security pays; this is the term $d\left(\mathrm{~s}^{\prime}\right)$, plus the value of reselling the security; this is the term $q\left(\mathrm{~s}^{\prime}\right)$.

\section{(iii) Central Banks and financial markets}

Central banks intervene in the financial markets by buying and selling securities. As an example, consider a one-dollar treasury bill that promises $(1+i)$ dollars next period. If we make the reasonable assumption that the U.S. government will not default on its promise, this security will pay $(1+i)$ dollars in every state. In the notation of Equation (3), the resale price of the bond, $q\left(s^{\prime}\right)$, is equal to 1 , and the coupon payment, $d\left(s^{\prime}\right)$, is equal to $i$.

To replicate the payoff of this bill using Arrow securities, a household would need to purchase a complete set of these securities. Applying the pricing Equation, (3), the interest rate, $i$, must be related to the prices of the Arrow securities by Equation (4),

$$
1=\sum_{s^{\prime}} Q\left(s, s^{\prime}\right)(1+i) .
$$

Rearranging this expression we see that the gross interest rate, $(1+i)$, is the inverse of the sum of the Arrow security prices,

$$
(1+i)=\frac{1}{\sum_{s^{\prime}} Q\left(s, s^{\prime}\right)} .
$$

By buying and selling securities on the open market, the Fed influences the pricing kernel. If the Fed raises the short rate, it will reduce the sum of all Arrow securities prices. If it lowers the short rate, the Fed will raise that sum. But how do those policy actions influence inflation and GDP? To answer that question, we must specify the preferences of the agents who hold financial assets and the technology for transforming one commodity into another.

\section{(iv) How $Q$ depends on preferences and technology}

$Q\left(s, s^{\prime}\right)$ is the price at which a household or a firm can trade a dollar today in state, $s$, for a dollar tomorrow, in state, $s^{\prime}$. It depends on the preferences of households, the endowments of labor and land, and the technology available for transforming goods today into goods tomorrow.

The core monetary model makes strong simplifying assumptions which imply that $Q\left(s, s^{\prime}\right)$ is a function of three things: the inflation rate, the growth rate of real GDP, and the conditional probability that state, $s^{\prime}$, will occur given that state, $s$, occurred today. ${ }^{8}$ I will represent the dependence of $Q$ on inflation, $\pi$, and growth, $\Delta y$, by a function $f\left[\pi\left(s^{\prime}\right), \Delta y\left(s^{\prime}\right)\right]$ where the properties of $f[\cdot]$ depend on assumptions about a complete macroeconomic model. Using this notation, we can write,

\footnotetext{
${ }^{8}$ To be more precise, $Q\left(s, s^{\prime}\right)$ depends on inflation and consumption growth. I ignore the distinction between GDP and consumption here, to keep the exposition simple. This simplification has a long history in the literature on monetary economics.
} 


$$
Q\left(s, s^{\prime}\right)=p_{s, s^{\prime}} f\left[\pi\left(s^{\prime}\right), \Delta y\left(s^{\prime}\right)\right]
$$

where, $p_{s, s^{\prime}}$ is the conditional probability that state, $s^{\prime}$ will occur.

If the representative agent has a simple, commonly assumed form of preferences, the function $f$ takes the form,

$$
f\left[\pi\left(s^{\prime}\right), \Delta y\left(s^{\prime}\right)\right]=\beta \frac{1}{\pi\left(s^{\prime}\right)} \frac{1}{\left(\Delta y\left(s^{\prime}\right)\right)^{\rho}}
$$

where $\rho$ is a non-negative number that is high when households dislike taking risks and $\beta$ is a number between 0 and 1 that describes impatience.

\section{(v) Monetary policy as a rule}

During the period from 1960 through 1979, the Fed raised the interest rate in response to inflation or rapid output growth and lowered it when inflation receded or when the economy was falling into a recession. Macroeconomists represent this policy by a reaction function,

$$
(1+i)=\psi[\pi(s), \Delta y(s)]
$$

where the notation $\psi[\pi(s), \Delta \mathrm{y}(s)]$ is shorthand for a function that describes how the central bank alters the interest rate in response to current inflation, $\pi(s)$, and current output growth, $\Delta y(s) .{ }^{9}$ What does the theory of rational expectations tell us about the inflation rate that would occur if the central bank were to set the interest rate using a policy reaction function like this?

Using equations (5) through (8), it follows that the inflation rate in each future state is linked to the interest rate in the current state by Equation (9),

$$
\frac{1}{\psi[\pi(s), \Delta \mathrm{y}(s)]}=\sum_{s^{\prime}} p_{s, s^{\prime}} f\left[\pi\left(s^{\prime}\right), \Delta \mathrm{y}\left(s^{\prime}\right)\right] .
$$

This is a stochastic version of a familiar expression that appears in undergraduate economics textbooks, the Fisher Equation. To see this, suppose that there is only one state and no growth so that $\Delta \mathrm{y}=1$. Using the connection between $(1+i)$ and $Q$ from Equation (5) and the functional form of $f[\cdot]$ from Equation (7), we can write

$$
\frac{1}{1+i}=\beta \frac{1}{\pi}\left(\frac{1}{1}\right)^{\rho}
$$

\footnotetext{
${ }^{9}$ The policy rule is often represented as a function of inflation and the difference of real GDP from target. This latter variable is called the output gap. I have substituted GDP growth for the output gap in this discussion since it simplifies the exposition of some key ideas without altering the substance of my argument.
} 
The left-hand-side of Equation (10) is the inverse of the gross interest rate and the right-handside is the special case of Equation (7) when there is one state and no uncertainty. Using this equation, I will illustrate how the Fisher equation and the central bank reaction function work together to determine inflation.

Replacing the interest rate in Equation (10) with the monetary rule from Equation (8), leads to Equation (11),

$$
\frac{1}{\psi(\pi, 1)}=\beta \frac{1}{\pi}
$$

The left-hand-side of this equation is a policy rule that determines the money interest rate as a function of current inflation. Because $\psi(\pi, 1)$ is an increasing function of $\pi$, an increase in current inflation leads to a fall in the price of a promise to deliver one dollar next period in every state. That price is represented by $q(s)$, the price of a pure discount bond. Since there is only one state, $q(s)$ is the inverse of the gross nominal interest rate $(1+i)$.

But although the left-hand-side of Equation (11) depends on the current inflation rate, the righthand-side depends on the expected future inflation rate. The current inflation rate is the relative of price of goods that were purchased yesterday in terms of today's goods. The expected future inflation rate is the relative price of today's goods in terms of tomorrow's goods. It is the important assumption of stationarity that allows me to use the same symbol for both concepts.

If current inflation increases, the central bank responds by raising the interest rate. This causes the left-hand-side of Equation (11) to decrease. If expected inflation increases, households will expect the terms of trade between today and tomorrow to be less favorable and that change in expectations causes the right-hand-side of Equation (11) to decrease. By choosing the policy rule, $\psi(\pi, 1)$, the central bank controls the steady state inflation rate.

Monetary policy in a stationary stochastic environment, where GDP may fluctuate, works the same way as the one-state example; but now there is a different inflation rate and a different growth rate in each state. In the case when there are two states, Equation (9) becomes a system of two equations in four unknowns,

$$
\begin{aligned}
& \frac{1}{\psi[\pi(a), \Delta \mathrm{y}(a)]}=p_{a, a} f[\pi(a), \Delta \mathrm{y}(a)]+p_{a, b} f[\pi(b), \Delta \mathrm{y}(b)] \\
& \frac{1}{\psi[\pi(b), \Delta \mathrm{y}(b)]}=p_{b, a} f[\pi(a), \Delta \mathrm{y}(a)]+p_{b, b} f[\pi(b), \Delta \mathrm{y}(b)] .
\end{aligned}
$$

The unknowns are $\pi(a)$ and $\pi(b)$, the inflation rates in states, $a$, and $b$, and $\Delta y(a)$ and $\Delta y(b)$, the growth rates in these states.

When the fundamentals enter state $a$, the economy grows at rate $\Delta \mathrm{y}(a)$, and the inflation rate is equal to the $\pi(a)$. When the fundamentals enter state $b$, the economy grows at rate $\Delta \mathrm{y}(b)$ and the 
inflation rate is equal to $\pi(b)$. To determine inflation in each state, we must break down monetary policy into its effects on inflation and its effects on growth. Since there are two equations and four unknowns we will need two more equations to determine all of the variables of interest.

\section{(vi) Inflation and growth in the core monetary model}

The relative impact of monetary policy on output and employment is an important question. But it is separate from the theory of rational expectations that I will address here. In the interests of making my points in the simplest way, I will explain how monetary policy affects inflation in the core monetary model. ${ }^{10}$ This model adds complete financial markets to an RBC model with a representative agent and flexible prices. Monetary policy has no impact on economic activity in this model either in the short-run or in the long run. Economic growth may vary from one period to the next in response to fluctuations in the state, but there is nothing that the central bank can do to influence those fluctuations.

Using the assumption that output growth is independent of monetary policy, I will set $s=\{a, b\}$ to represent the possibility that growth may be high or low. We now have two new equations to supplement the system (12),

$$
\begin{aligned}
& \Delta y(s)=\Delta y_{a}, \\
& \Delta y(s)=\Delta y_{b},
\end{aligned}
$$

where $\Delta y_{a}$ and $\Delta y_{b}$ are numbers that represent the growth rate in states $a$ and $b$. Equations (12) and (13) together explain all four variables, $\pi(a), \pi(b), \Delta y(a)$ and $\Delta y(b)$.

Suppose that the central bank follows the policy rule

$$
\psi[\pi(s), \Delta y(s)]=\bar{I} \pi(s)^{\eta} \Delta y(s)^{\phi},
$$

where $\bar{I}$ is the interest rate that would be chosen if inflation was zero, and $\eta$ and $\phi$ are reaction coefficients. I will refer to $\bar{I}$ as the zero-inflation target.

\footnotetext{
${ }^{10}$ Farmer (2006, 2008, 2010, 2012a,b) constructs a real model with incomplete factor markets and Farmer (2010, 2013) develops a monetary model with incomplete factor markets where a belief function replaces the assumption that output is exogenous. Kocherlakota (2012) drops the labor supply equation, as in Farmer (2006, 2008), but he does not provide an explicit theory to explain how multiple unemployment rates can be supported as equilibria in a model of profit seeking firms as in Farmer (2006, 2008, 2010, 2012a,b). New-Keynesian's (see for example, Clarida et. al. 1999) replace the exogenous output assumption by the New-Keynesian Philips curve, an equation that links prices and quantities. Farmer (2013) shows that the incomplete factor market model provides a better fit to the data than the New-Keynesian model because it is able to account endogenously for persistence in the unemployment rate. For an excellent critique of the new-Keynesian approach from a classical perspective, see Chari-KehoeMcGrattan (2009).
} 
Rules like this are called Taylor Rules after the economist John Taylor (Taylor 1993) who showed that they do a good job of explaining the behavior of actual monetary policy in the U.S. in the post-war period. The reaction coefficients have the interpretation that if inflation were to increase by $1 \%$, the central bank would respond by increasing the interest rate by $\eta \%$ and if growth increased by $1 \%$, it would raise the interest rate by $\phi \%$.

\section{(III) Part 2: Explaining the data with the core monetary model}

In Part 2, I will explain the history of inflation since WWII, using a calibrated version of the core monetary model and I will show that a more aggressive interest rate rule leads to lower and less volatile inflation. Then I will show how unconventional monetary policy can be used to prevent price deflation when the central bank is constrained by the zero lower bound.

\section{(i) Using the core monetary model to explain conventional monetary policy}

Here, I will examine how different values of $\bar{I}, \eta$ and $\phi$, affect the inflation rate in different states in a rational expectations equilibrium. ${ }^{11}$ Despite the simplicity of my example, where output growth in each state is independent of inflation, the ideas I will describe carry over to more realistic models in which central bank policies affect, not only inflation, but also GDP and real economic activity.

Table 1 summarizes the values of the time preference parameter, the risk aversion parameter, and the probabilities that the economy will stay either in state $a$, or in state $b$. I have assumed that state $a$ is a high growth state in which GDP grows by $4 \%$ per year and that state $b$ is a low growth state where GDP growth is $1 \%$.

\begin{tabular}{|c|c|c|c|c|c|}
\hline Table 1 & \multicolumn{5}{|c|}{ Assumptions about model parameters } \\
\hline $\begin{array}{c}\text { Time } \\
\text { preference }\end{array}$ & $\begin{array}{c}\text { Risk } \\
\text { aversion }\end{array}$ & $\begin{array}{c}\text { Probability of } \\
\text { staying in state } \\
a\end{array}$ & $\begin{array}{c}\text { Probability of } \\
\text { staying in state } \\
b\end{array}$ & $\begin{array}{c}\text { Growth rate in } \\
\text { state } \\
a\end{array}$ & $\begin{array}{c}\text { Growth rate in } \\
\text { state } \\
b\end{array}$ \\
\hline \hline$\beta$ & $\rho$ & $p_{a, a}$ & $p_{b, b}$ & $\Delta \mathrm{y}(a)$ & $\Delta \mathrm{y}(b)$ \\
\hline 0.97 & 2.0 & 0.9 & 0.95 & $4 \%$ & $1 \%$ \\
\hline
\end{tabular}

Table 2 compares two different policy rules, chosen to illustrate the difference between the policies followed before 1979 and after 1982. The zero-inflation target is $5 \%$ for both policies but in row 1 the Fed chooses an inflation reaction coefficient of $\eta=1.1$ and in row 2 it chooses a larger coefficient of $\eta=2.0$.

\footnotetext{
11 The values of inflation and the interest rate reported in Tables 2 and 4 are the solutions to the non-linear equations (12) and (13), computed using Matlab. The code is available from the author on request.
} 


\begin{tabular}{|c|c|c|c|c|c|c|}
\hline Table 2 & \multicolumn{6}{|c|}{ The effect of changing the inflation response } \\
\hline $\bar{I}$ & $\eta$ & $\phi$ & $\pi(a)$ & $\pi(b)$ & $I(a)$ & $I(b)$ \\
\hline \hline 1.05 & 1.1 & 0 & $37.7 \%$ & $13.6 \%$ & $49.2 \%$ & $20.8 \%$ \\
\hline 1.05 & 2 & 0 & $5.1 \%$ & $0.06 \%$ & $15.9 \%$ & $6.4 \%$ \\
\hline
\end{tabular}

Row 1 is an example of a less aggressive monetary policy of the kind that was followed before 1979 and row 2 is a more aggressive policy of the kind followed after $1982 .{ }^{12}$ Notice that the less aggressive monetary policy leads to inflation rates in states $a$ and $b$ of $37.7 \%$ and $13.6 \%$ with corresponding interest rates of $49.2 \%$ and $20.8 \%$. These inflation rates are high and volatile.

Contrast this with the policy of the more aggressive regime (row 2) which leads to inflation rates of $5.1 \%$ and $0.06 \%$ and interest rates of $15.9 \%$ and $6.4 \%$, numbers which are smaller and less volatile than those in row 2 . The only difference between these two examples is the inflationreaction coefficient of the policy rule. It follows that a central bank can produce low and stable inflation in the model environment by choosing a policy rule with a high inflation-reaction coefficient.

This result corresponds to what econometricians have found (for example, Lubik and Schorfheide 2004) when examining the time series data. During the period from 1960 through 1979, monetary policy was less aggressive and inflation was high and variable. During the period after 1982, policy was more aggressive and inflation was lower and less volatile.

\section{(ii) Why does a more aggressive rule lead to lower inflation?}

There are two important pieces to the argument I have given for why a more aggressive inflationreaction coefficient leads to lower and less volatile inflation. The first is the assumption that households form rational expectations. The second is that the central bank follows a rule.

Suppose that the central bank raises the short-term interest rate. Since the real interest rate is pinned down by the fundamentals of the economy, expected inflation must increase to maintain the no arbitrage condition. The return on a nominal bond, risk adjusted, must appear equally as attractive as an investment in a real asset.

\footnotetext{
${ }^{12}$ Some estimates place the parameter $\eta$ less than 1 . This is called a passive policy in the literature as opposed to a value greater than 1 that is called active. I have not gone all the way to a passive monetary policy in my simulations since passive policies introduce an additional complication; there may be additional non-fundamental states in a steady state. For a full discussion of this possibility in the context of U.S. monetary policy, see the article by Clarida, et al (2000).
} 
Expected inflation can increase in one of two ways. The current price of goods, holding fixed the expectation of future goods prices, can fall. Or the expected future price of goods, holding fixed current goods prices, can increase. In a flexible-price rational expectations model with forward-looking agents, both channels are operative.

For a given sequence of shocks, an aggressive policy rule leads to less inflation variability because it allows adjustment of real rates of return, caused by real shocks, to occur through a change in the nominal interest rate, rather than through a change in inflation.

\section{(iii) The problem with conventional monetary policy at the zero lower bound}

One of the lessons of post-war monetary policy is that policies are best modeled as rules rather than as discretionary events. Expectations matter, and when the central bank repeats the same actions in the same circumstances, agents in the economy learn to respond in a particular way. But monetary policy rules are not set in stone. They can and do change from time to time as policy evolves in response to changing circumstances and as policy makers learn from experience. When the policy-rule changes, there will be a period where households and firms learn to respond to the new rules of the game. The current crisis has engendered one such period of adaptation and change as the rule used to conduct policy over the past thirty years has broken down.

The need to adapt monetary policy to a new set of circumstances has led to a dilemma since the rule that worked well in the period after 1982 cannot easily be adapted to the current crisis in which the interest rate is close to zero. The following example illustrates this dilemma by showing that an alternative rule might have prevented a sharp drop in inflationary expectations like the one that occurred after the bankruptcy of Lehman Brothers in 2008. But moving to an alternative rule cannot be achieved through conventional means.

I will illustrate the dilemma by means of an example. Table 3 shows the parameters for a simulated economy that grows at $4 \%$ in a state $a$, but where it shrinks by $5 \%$ per year in state $b$. All other parameters in this Table are the same as for the previous example.

\begin{tabular}{|c|c|c|c|c|c|}
\hline Table 3 & \multicolumn{5}{|c|}{ Modeling a recession } \\
\hline $\begin{array}{c}\text { Time } \\
\text { preference }\end{array}$ & $\begin{array}{c}\text { Risk } \\
\text { aversion }\end{array}$ & $\begin{array}{c}\text { Probability of } \\
\text { staying in state } \\
a\end{array}$ & $\begin{array}{c}\text { Probability of } \\
\text { staying in state } \\
b\end{array}$ & $\begin{array}{c}\text { Growth rate in } \\
\text { state } \\
a\end{array}$ & $\begin{array}{c}\text { Growth rate in } \\
\text { state } \\
b\end{array}$ \\
\hline \hline$\beta$ & $\rho$ & $p_{a, a}$ & $p_{b, b}$ & $\Delta \mathrm{y}(a)$ & $\Delta \mathrm{y}(b)$ \\
\hline 0.97 & 2.0 & 0.9 & 0.95 & $4 \%$ & $-5 \%$ \\
\hline
\end{tabular}

Under these assumptions about growth rates, the policy rule described by Equation (14), and the reaction functions from Table 2, leads to situations where the central bank would need to choose a negative nominal interest rate in state $b$. Since the interest rate cannot be negative, this set of 
fundamentals leads the central bank into a situation where the interest rate cannot be lowered further. To represent this constraint, I have amended the policy rule, Equation (14), as follows,

$$
\psi[\pi(s), \Delta y(s)]=\max \left[\bar{I} \pi^{\eta} \Delta y^{\phi}, 1\right] .
$$

This rule bounds the gross return $(1+i)$ to be no smaller than 1 by setting the short-term interest rate to zero in those situations where a policy maker, following Equation (14), would prefer to choose an interest rate that was negative.

Table 4 shows what would happen to inflation in this economy under two possible choices for the Taylor rule. In both cases, the Fed chooses an inflation response coefficient of 2; but the zero-inflation target differs across the two policies. Both rules impose the zero lower bound.

Row 1 shows what would happen to inflation in both states when the zero-inflation target is $5 \%$, represented by setting the parameter $\bar{I}$ equal to 1.05 . Row 2 shows the outcome when it is set to negative $1 \%$. Under the $5 \%$ rule, we see that there would be deflation in state $b$ of $2.4 \%$. But if the Fed were to move to rule 2 with a negative zero-inflation target, there would be a mild inflation in state $b$ of $0.05 \%$. Both rules hit the zero lower bound for the interest rate in state $b$. The difference in inflation across the two rules is enforced by what households and firms expect the Fed to do in the future.

\begin{tabular}{|c|c|c|c|c|c|c|}
\hline Table 4 & \multicolumn{5}{|c|}{ The effect of changing the zero-inflation target } \\
\hline $\bar{I}$ & $\eta$ & $\phi$ & $\pi(a)$ & $\pi(b)$ & $I(a)$ & $I(b)$ \\
\hline \hline 1.05 & 2 & 0 & $3.4 \%$ & $-2.4 \%$ & $12.3 \%$ & $0 \%$ \\
\hline 0.99 & 2 & 0 & $9.3 \%$ & $0.05 \%$ & $18.3 \%$ & $0 \%$ \\
\hline
\end{tabular}

At the zero lower bound, households are willing to hold money or bonds even though both assets pay a zero nominal return. But although the nominal return is zero, the real return depends on current and future prices. In the example I have constructed, the real return between the current state and alternative future states depends on real shocks. The price of current goods, relative to future goods, adjusts to assure that money and bonds are willingly held.

Recall that, in a stationary rational expectations equilibrium, current prices are influenced by beliefs about future prices. By managing expectations about its future actions, a central bank can influence current prices. The following section shows that the central bank can signal changes in its future intentions by influencing the prices of assets other than short-term treasury bills, when conventional policy actions are constrained by the zero lower bound. 


\section{(iv) Using the core monetary model to explain unconventional monetary policy}

Much of the recent policy debate on unconventional monetary policy has focused around the issue: How can the Fed signal its intention to change future monetary policy in a credible way? The credibility issue arises because, when the interest rate is zero, there is no way to signal a change of policy to the markets using conventional open market operations. The purchase and sale of treasury bills has no effect on the economy, because when the interest rate is zero, treasury bills and base money become perfect substitutes. Monetary policy becomes like "pushing on a string". That's where unconventional monetary policy comes in.

The two policies described in Table 4 both result in a zero interest rate in state $b$. That causes a problem for a central bank that wishes to signal a change in policy, since it is expectations of future policy that enforce a particular inflation rate in the current period.

Suppose that the central bank has been following rule 1 for a period and that the public has conditioned its expectations on the assumption that rule 1 will continue to be used in the future. That rule leads to a deflation of $2.4 \%$ in a deep recession, an outcome that is undesirable to a policy maker who would prefer to maintain a positive inflation rate.

Let us suppose that, finding itself in a situation of deflation, the Fed would like to switch to rule 2. A move to rule 2 , while in state $b$, leads to a policy dilemma. The bank cannot credibly signal its switch to the new rule by buying or selling treasury bills since both rules lead to a zero interest rate in that state.

But although both rules lead to the same interest rate in state $b$; they are associated with different pricing kernels. If we let $Q_{1}\left(s, s^{\prime}\right)$ be the pricing kernel under policy 1 and $Q_{2}\left(s, s^{\prime}\right)$ be the pricing kernel under policy 2 then, it is true that

$$
Q_{i}\left(b, a^{\prime}\right)+Q_{i}\left(b, b^{\prime}\right)=1, \quad \text { for } \quad \mathrm{i}=1,2 .
$$

That is simply the statement that the interest rate is equal to zero in state $b$ under both policy rules. But that does not imply that this equality holds for each security, in other words,

$$
Q_{1}\left(b, a^{\prime}\right) \neq Q_{2}\left(b, a^{\prime}\right) \text { and } Q_{1}\left(b, b^{\prime}\right) \neq Q_{2}\left(b, \mathrm{~b}^{\prime}\right)
$$

The inequalities in (17) reflect differences in the prices of the Arrow securities at the lower bound across the two policy rules. These inequalities imply that there will exist financial securities, other than treasury bills, that have different prices if the Fed follows Rule 2 from those that would hold if it follows Rule 1. One example is a long-term government bond; another is a mortgage-backed security issued by the private sector. By intervening in the markets for these alternative assets, a central bank can signal its intent to operate a different policy rule in future states. 


\section{(IV) Part 3: Some evidence in support of policy effectiveness}

\section{(i) The effect of QE1 on inflationary expectations}

The theory of financial markets in a stationary environment predicts that central bank interventions in the asset markets can influence asset prices. ${ }^{13}$ But what evidence is there that these kinds of interventions have worked in practice?

Figure 1 shows how the Federal Reserve Bank responded to the recession that began in December of 2007 and escalated rapidly in September of 2008. The figure breaks down the balance sheet of the Fed into three separate components, short-term treasury securities, mortgage securities and other securities. Much of this last component consists of loans to the holding company, Maiden Lane, created specifically to rescue the financial sector.

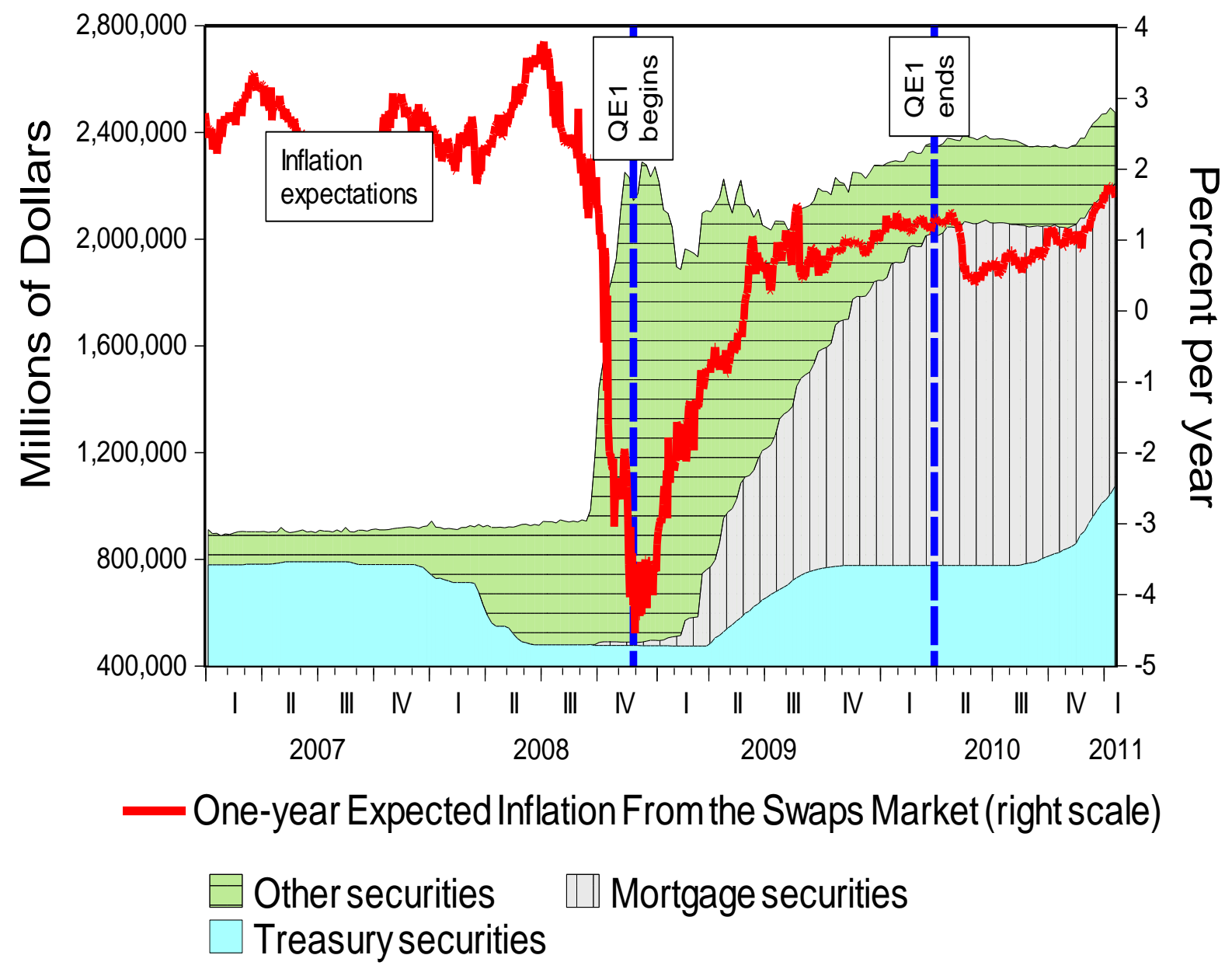

\footnotetext{
${ }^{13}$ Eggertsson and Woodford (2003) have argued that the composition of the Fed's balance sheet is irrelevant in a complete markets economy like the one used in my example. But their irrelevance proposition does not preclude the use of changes in the Fed's balance sheet as a signal to the public that the policy rule has changed and that the Fed's reaction to inflation in future states will be different.
} 
Notice from Figure 1, that the balance sheet of the Fed increased from approximately $\$ 800 \mathrm{~b}$ in 2007 to over $\$ 2,000$ b immediately following the Lehman Brothers bankruptcy in September of 2008. This increase did not arise from the purchase of short-term treasury securities, the method of operating monetary policy in normal times; it arose instead from the purchase of risky securities that pay different amounts in different states. ${ }^{14}$ In terms of the theory developed in this paper, this implies that the Fed was not buying an equal weighted basket of all Arrow securities. It was buying a basket with very different payouts across alternative states of nature.

Figure 1 also shows a measure of one-year inflation expectations taken from a derivate security in the asset markets. This is the value of expected inflation implied by a swap in which one party makes a payment to the other at the end of the contract. ${ }^{15}$ On December $2^{\text {nd }} 2008$ expected inflation from the one year swap market was $-4.5 \%$. Traders were pricing a large expected deflation into their behaviors. From that date on, inflationary expectations increased steadily returning to the range of plus $1 \%$ by the fall of 2009 . It is unlikely that the correlation between the change in expectations, and the implementation of the new policy of quantitative easing which immediately preceded it, was coincidental.

\section{(ii) The effect of QE1 on the stock market}

Under the policy of quantitative easing, the Fed has purchased two major classes of assets; agency-guaranteed mortgage-backed securities and long-term government bonds. Long-term treasury bonds and mortgage-backed securities can both be expressed as weighted sums of Arrow securities; they differ only in the weights attributed to each state dependent payoff. The fact that these weights are different implies that Fed purchases of long bonds will impact the securities markets differently from Fed purchases of mortgage-backed securities.

14 Although the mortgage-backed securities purchased by the Fed were guaranteed by the Federal government, there is still substantial prepayment risk that is correlated with the incidence of individual defaults and, therefore, with the state of the economy. And although Ginnie Mae MBS are backed by the "full faith and credit obligation" of the Federal government, Freddie Mac and Fannie Mae are not.

Importantly, even though most MBS and agency securities held by the Fed are liabilities of Fannie Mae and Freddie Mac, and the two agencies were placed into government conservatorship in September 2008, these securities are not the equivalent of US Treasuries. They do carry a very strong guarantee by the US Treasury. But the Treasury's "credit enhancement" is not the same as the legally binding "full faith and credit" obligation of the US government that backs Treasury securities. Goodfriend 2011, page 3. (Goodfriend is quoting a Washington Post article, Goldfarb, 2010).

${ }^{15}$ In an earlier version of this paper I used a measure of inflation derived from the difference between the nominal yield on a five-year bond and the real TIPS yield. I am indebted to Hanno Lustig for providing me with data from a one-year swap. Fleckenstein et al (2010) argue that this is a better measure of expected inflation due to pricing anomalies in the TIPS yields around the time of the Lehman bankruptcy. 
Fed purchases of five-year or ten-year treasury bonds have their most direct effect on the prices of corporate bonds of a similar maturity; these private debt instruments represent combinations of Arrow securities with a similar weighting pattern to those of equal maturity government debt instruments. In contrast, mortgage-backed securities have high payoffs when the economy is strong since in these states there will be fewer mortgage defaults. The prices of mortgage-backed securities should move closely with the prices of equity shares in private corporations since both classes of assets have high payoffs when the economy recovers.

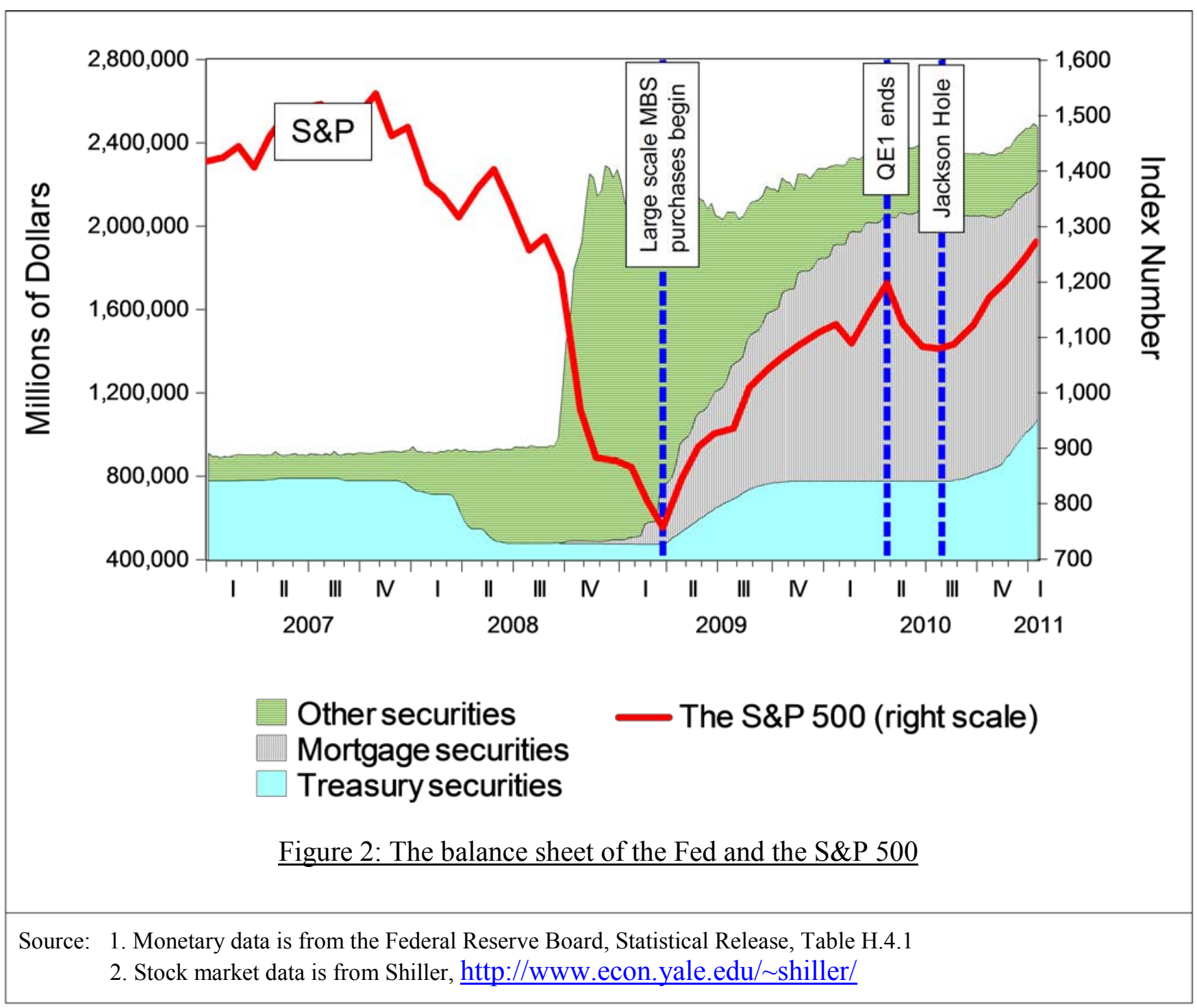

Unconventional monetary policy began in December of 2007 with the creation of the Term Auction Facility (TAF) whereby the Fed auctioned term loans against a wide variety of collateral in an effort to ease credit market conditions. This shows up on Figure 1 as the substitution on the balance sheet of 'other securities' for short-term treasury debt. But it was not until the bankruptcy of Lehman brothers in September of 2008 that policy involved a significant 
expansion of the balance sheet. Although the extension of credit may have had some effect on the stock market, the magnitude of interventions during this period is dwarfed by the subsequent interventions in the fall of 2008 that followed the authorization of a $\$ 700$ billion dollar troubled asset relief program (TARP).

Some evidence for the effects of TARP is provided in Figure 2. Notice the close connection between the end of a bear market in March of 2009 and the beginning of large-scale purchases in the MBS market, which began in September of 2008 but which did not pick up steam until the first quarter of 2009. Notice also that the bull market ended with a sharp reversal in April of 2010, a date that coincides with the removal of the Fed program to purchase risky assets. ${ }^{16}$

The announcement of a second round of quantitative easing occurred at the Jackson Hole conference in August of 2010. Although the policy itself did not begin until November of the same year, Figure 2 illustrates that the announcement of the policy coincides closely with the date at which there was another major reversal in the stock market. ${ }^{17}$

\section{(V) Conclusion}

The core monetary model adds a complete set of financial markets to the classical monetary model. I have shown that this core monetary model explains both conventional and unconventional monetary policy and that it provides a guide to the design of good monetary policy rules.

Using the core monetary model, I have shown that unconventional monetary policy, implemented through the large scale purchase of mortgage-backed securities and long term government bonds, was effective in preventing deflation at the zero lower bound. The policy worked by signaling the intent of future policy actions to traders in the financial markets. Because the policy of asset market purchases acts as a signal of future intent, it is complementary to alternative communication strategies such as the publication of the inflation expectations of Fed policy makers.

The practice of central banking and the development of new economic ideas are part of an evolutionary process that is fed by economic events. Large disruptive events are few and far between. The financial panic of 1907 led to the creation of the Fed. Since its inception, the Fed, along with other central banks worldwide, has been accumulating knowledge about the structure of the economy and applying that knowledge in its day-to-day operations.

\footnotetext{
${ }^{16}$ Kuttner (2006) finds evidence of the effectiveness of Fed policies on long bond prices over the period from 1941 through 2003. For a comprehensive study of the effects of QE in the most recent period, using an event study, see Krishnamurthy and Vissing-Jorgensen (2012). See also, Gagnon et al (2011).

${ }^{17}$ There is evidence, Farmer (2012b), that the ability of the Fed to influence the stock market does not just feed into inflation expectations as in the model developed in this paper. It also influences the unemployment rate. Farmer (2012a,2103) provides a theory to explain the channel by which this operates.
} 
The Great Depression of the 1930's led to widespread agreement that government has an obligation to maintain full employment. In the U.S., this idea was enshrined in the Employment Act of 1946. Since that date, the Fed intervened actively to shorten recessions by lowering the interest rate when signs of weakness appeared. Casual inspection of the data suggests that this policy has been effective as postwar business cycles have been considerably less volatile than those that preceded them in the nineteenth and early twentieth centuries.

The appearance of stagflation in the 1970s led to a second change in policy as the Fed began to adopt a more aggressive response to inflation. Academic economists responded by developing the theory of rational expectations and by arguing that central banks should follow policy rules. Central banks responded by adopting inflation targeting and by following more aggressive rules to stabilize inflation. The change from less aggressive to more aggressive responses to nascent inflation was accompanied by a reduction in the volatility of U.S. business cycles.

The Great Recession is a further game-changing event. In the wake of the 2008 financial crisis, we have seen policy makers experiment with unconventional monetary policy in an attempt to regain control of inflation and unemployment in an environment where traditional policy instruments no longer work. My contribution in this paper has been to provide a unified framework, the core monetary model, to understand how an interest rule can be used to control inflation in normal times, and to explain the purpose of unconventional monetary policy when policy attains the zero lower bound. Unconventional monetary policy is an important tool in a central bank's arsenal that can be used to help prevent deflation in the wake of a financial crisis. 


\section{References}

Arrow, Kenneth J., "The Role of Securities in the Allocation of Risk Bearing", The Review of Economic Studies, 31(2), pp. 91-96, 1964

Bernanke, B. and F. Mishkin, "Central bank behavior and the strategy of monetary policy: Observations from Six Industrialized Countries," NBER Macroeconomics Annual, pp. 183-228, 1992

Beyer, Andreas and Roger E. A. Farmer, "Natural Rate Doubts", joint with Andreas Beyer, Journal of Economic Dynamics and Control, 31, pp. 797-825, 2007

Chari, V.V., Patrick Kehoe and Ellen McGrattan. "New Keynesian Models: Not Yet Useful for Policy Analysis”, American Economic Journal: Macroeconomics 1(1), pp. 242-266, 2009

Clarida, Richard, Jordi Galí and Mark Gertler. "The Science of Monetary Policy: A New Keynesian Perspective”, Journal of Economic Literature, 37, pp. 1661-1707, 1999

"Monetary Policy Rules and Macroeconomic Stability: Evidence And Some Theory", Quarterly Journal of Economics, 115(1), pp. 147-180, 2000

Cooley, Thomas F \& Hansen, Gary D. "The Inflation Tax in a Real Business Cycle Model," American Economic Review, 79(4), pp. 733-748, 1989

Cúrdia, Vasco and Michael Woodford. "Conventional and Unconventional Monetary Policy", Federal Reserve Bank of St. Louis Review, 92(4) pp. 229-264, 2010

Eggertsson, Gauti B. and Michael Woodford, "The Zero Bound on Interest Rates and Optimal Monetary Policy", Brookings Papers on Economic Activity, Economic Studies Program, The Brookings Institution, 34(1) pp. 139-235, 2003

Farmer. Roger E. A., "The Lucas Critique, Policy Invariance and Multiple Equilibria” Review of Economic Studies, 58, pp 321-323 1991

, "Why Does Data Reject the Lucas Critique?" Annales d'économie et de statistique, special issue on "The Econometrics of Policy Evaluation", pp. 67-68. 2002

, "Old Keynesian Economics", UCLA mimeo, Paper presented at a conference in honor of Axel Leijonhufvud, held at UCLA on August 30th 2006, available online at http://rogerfarmer.com/NewWeb/Working\%20Papers/OldKeynes-09-21-06.pdf

, "Old Keynesian Economics", in Macroeconomics in the Small and the Large, Roger E. A Farmer ed., Edward Elgar, London, 2008

, Expectations Employment and Prices, Oxford University Press, Oxford, 2010 

$172,2012 \mathrm{a}$

, "Confidence, Crashes and Animal Spirits", Economic Journal, (122) pp. 155-

, "The Stock Market Crash of 2008 Caused the Great Recession: Theory and Evidence", Journal of Economic Dynamics and Control, (36) pp. 693-707, 2012b

, "Animal Spirits, Persistent Unemployment, and the Belief Function," forthcoming in Roman Frydman and Edmund S. Phelps (eds.), Rethinking Expectations: The Way Forward for Macroeconomics, Princeton, N.J.: Princeton University Press, 2013

Federal Reserve Bank of Richmond, (2001), Economic Quarterly, Special Issue "The 50" Anniversary of the Treasury-Federal Reserve Accord," Winter, 2001

Fleckenstein, Matthias, Francis A. Longstaff and Hanno N. Lustig, "Why Does the Treasury Issue TIPS? The TIPS-Treasury Bond Puzzle", Available at SSRN:

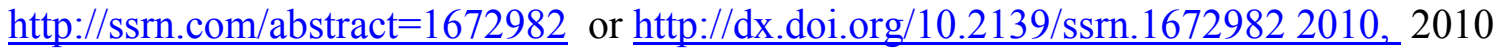

Gagnon, Joseph, Matthew Raskin, Julie Remache, and Brian Sack, "The Financial Market Effects of the Federal Reserve's Large-Scale Asset Purchases", International Journal of Central Banking, pp. 3-43, March, 2011

Goldfarb, Zachary .A. "Rep. Barney Frank Warns of Fannie, Freddie Risks.” The Washington Post, A10 March 6, 2010

Goodfriend, Marvin, "Central banking in the credit turmoil: An assessment of Federal Reserve practice. Journal of Monetary Economics, 58, pp. 1-12, 2011

Kocherlakota, Narayana R. "Incomplete Labor Markets", Federal Reserve Bank of Minneapolis mimeo, March 2012

Krishnamurthy, Arvind and Annette Vissing-Jorgensen. "The Effects of Quantitative Easing on Interest Rates: Channels and Implications for Policy,", Brookings Papers on Economic Activity, presented in Fall 2011, forthcoming, 2012

Kuttner, Kenneth N. "Can Central Banks Target Bond Prices", In Chung, ed., Monetary Policy in an Environment of Low Inflation, Seoul: The Bank of Korea, 2006

Lubik, Thomas A. and Frank Schorfheide. "Testing for Indeterminacy: An Application to U.S. Monetary Policy”, American Economic Review, 94(1) pp. 190-217, 2004

McConnell, Margaret M. and Gabriel Perez-Quiros. "Output fluctuations in the United States: What has Changed Since the Early 1980's?" American Economic Review, 90(5), pp. 1464-1476, 2000 
Sims, Christopher and Tao Zha. "Were there Regime Switches in U.S. Monetary Policy", American Economic Review, 96(1), pp. 54-81, 2006

Stock, James and Mark Watson. "Has the Business Cycle Changed and Why?" NBER Macroeconomics Annual pp. 159-218, 2002

Taylor, John B. "Discretion versus Policy Rules in Practice," Carnegie-Rochester Conference Series on Public Policy, 39, pp.195-214, 1993 